\title{
Intellectual Capital Performance Indicators for Complex Project Management
}

\author{
Mario Štorga $^{\mathrm{a}}$ and Stanko Škec ${ }^{\mathrm{a}}$ \\ ${ }^{a}$ University of Zagreb, Faculty of Mechanical Engineering and Naval Architecture, \\ Ivana Lučića 5, 10000 Zagreb, Croatia \\ "Corresponding Author's Email: mario.storga@ffsb.hr
}

\section{Introduction}

The existence of gap between theory and practice for complex R\&D project management (by means of organizational, technological, and informational complexity) represents serious obstacle for both researchers and industry. Many of existing methods and tools for project management are not appropriate for complex $\mathrm{R} \& \mathrm{D}$ projects, though they are persistently used. To illustrate this, for example majority of the methods and tools for risk management in complex R\&D projects are extremely subjective and perceive risk exclusively as two-dimensional phenomenon (probability and impact) (Hall 2011). Probability-impact risk model is still prevailing (Taroun 2013) and many methods (AHP, MCDM, FMEA, etc.) use that model as an underlying basis, without taking into consideration complex causal, dependency and influence interrelations between specific risk elements.

Technological aspect of complex R\&D project management is widely recognised and it is common practice to deal with complex project performance measures that can be recognized and described formally based on the tangible outputs. Also, tangible outputs of the communications and the information objects generated as part of the complex projects are fundamentally related to performance and analysis of their content can provide understanding, insights and predictions about the complex project (Hicks, 2013). However, a number of project management factors is often intricately linked and cannot be described by using only tangible aspects. For the effective complex project management there is necessity to embrace also the socio-technical perspective - human related issues and organizational complexity.

Interdependence and high levels of connectivity within organization hierarchical levels (individuals, teams, etc.) can result in non-linear organisational behaviour what was already tackled by many researchers such as (Ackermann and Eden 2001). Also, recent complex R\&D project management studies indicated consequences of non-linear organisational behaviour, such as emergence of vicious innovativeness, knowledge growth and risks cycles and patterns (Remington and Zolin 2010, Noruzy at al. 2013), but without necessary theoretical grounding and explanation. To increase understanding on those emerging phenomenon and facilitate advanced complex R\&D project management in general, there is need to expand and improve existing models, methods, and tools.

Therefore, the objective of research within the VISINEV (www.visinev.org) project framework, which first results are presented in this paper, has been set as follows:

1. To investigate the nature of the socio-technical interactions between individuals and teams in hierarchical $R \& D$ organizations performing the complex R\&D projects, with the goal to provide foundation for modelling the non-tangible outcomes dynamics.

2. To visually represent and analyse dynamics of non-tangible outcomes of the complex R\&D projects and their interaction in order to supplement existing complex R\&D project management tools.

\section{Current understanding}

Traditional project management approaches are often ignoring "soft" management elements (mind set, behaviour, culture and trust). However, complex R\&D project management practice could be seen as 
a social conduct, defined by history, context, individual values and wider structural framework actuality of the project (Cicmil 2006). From the project performance management literature corpus still remains an open question of measuring a resource whose nature is intangible and non-financial. Many researchers (e.g. Verbano and Crema 2013) argued that new methods and performance indicators are needed for the managers which are interested to the organization's intangible assets, in order to provide support to the problem solving and decision-making processes as well as to enable understanding of emergent phenomenon influencing organisational output at the market level (competitiveness, innovation and growth). Consequently, there is a need to extend and supplement present R\&D projects key performance indicators by those whose focus are components of intellectual capital (human, structural and relational capital) and to model and predict their evolution during the complex R\&D project execution (Figure 1).

\section{Research methods}

The research presented in the paper was built on state of the art principles for intellectual capital performance measurement within the $R \& D$

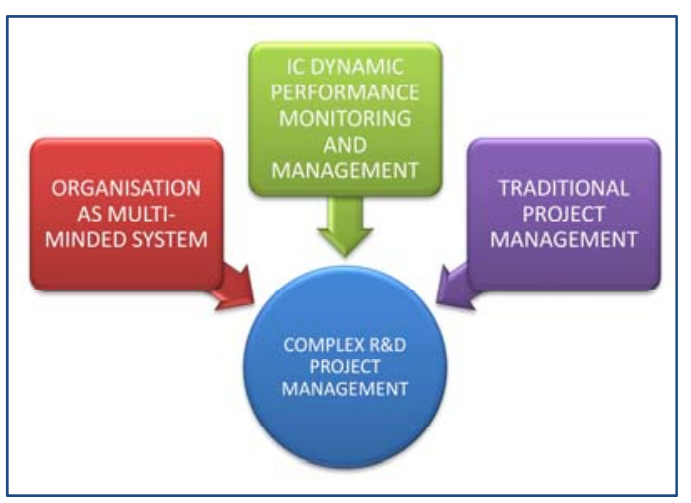

Figure 1: Research scope organisation environment. After defining the problem, the intellectual capital measurement perspectives and criteria were explored, and the list of the preliminary list of the indicators was developed. Questionnaire was used to validate the preliminary list with the group of the experts in industry. That was followed by analysis of the cause and dependency relationships between the indicators and by building the network model that was validated within the group of the experts from academia.

\section{Results}

\section{List of the key performance indicators for intellectual capital elements in R\&D organisations}

As the first step of the research, framework for the modelling of the intellectual capital elements evolution within R\&D organisations is established (Figure 2). Key performance indicators for the intellectual capital elements are recognised as the measure of the individual and team performance level, contributing indirectly to the organisational performance at the market

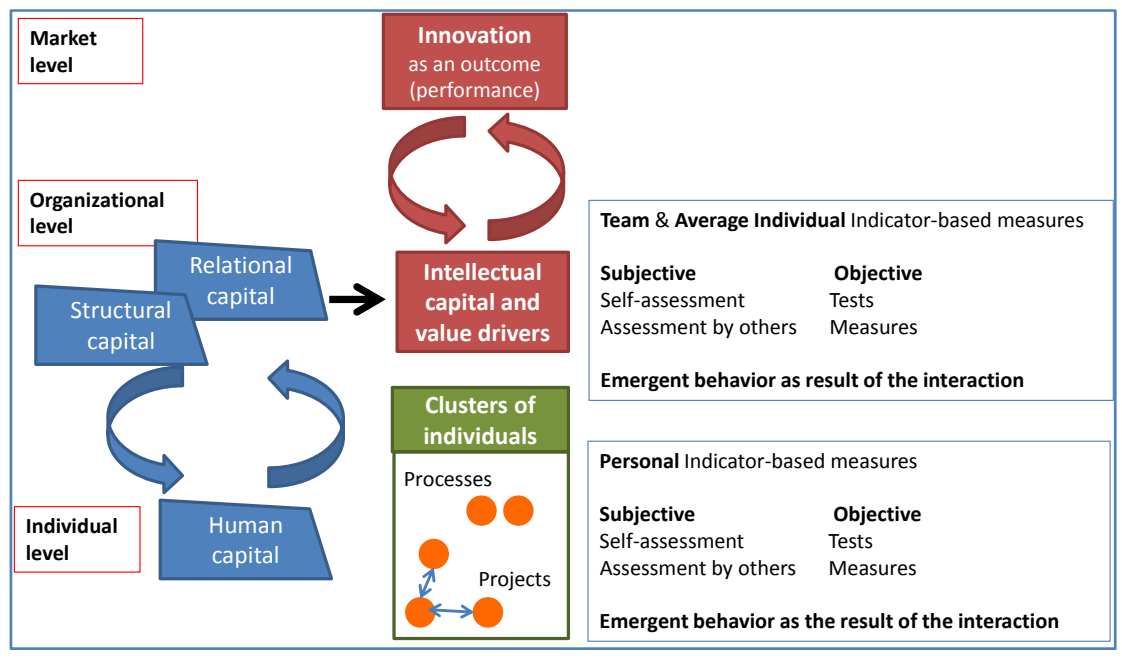

Figure 2: Intellectual capital elements within organisation levels level.

From the extensive literature review, more than 400 key performance indicators related to the intellectual capital were extracted (Gonzaleez-Loureiro M. and Figueroa Dorrego P. 2012). During the evaluation phase, the number is reduced to the 65 indicators relevant for the context of the R\&D projects. The indicators has been defined as leading which are, by their definition, input - oriented and harder to measure, but much easier to influence and correct if needed during the complex R\&D projects execution. Indicators were in the further research classified into 4 categories describing their 
relevance for the elements of the intellectual capital that have been set as a target in the project: competences and knowledge development; communication and information exchange; innovativeness and ideation capability; and motivation and satisfaction. Indicators were also classified accordingly to the presumed frequency of the change into those with annually, quarterly, monthly and daily dynamics. In order to make them related to the R\&D projects' context, they were classified accordingly to the granularity level of the R\&D process elements that should be considered as relevant for measuring values that are relevant for studying indicators' change dynamics (portfolio, project, phase, task level). Proposed indicators list was evaluated and verified by industrial partners from automotive industry supplier and energy production and distribution related systems-services sector.

\section{Influence network of key performance indicators for intellectual capital elements in R\&D organisations}

\section{Different performance indicators within and between different hierarchical levels in organisation are mutually interconnected by causal and dependency relations describing the nature of the emerging phenomenon of the complex project performance in R\&D organisation. In order to grasp the wider picture and set up the stage for the real- time project} performance measurement and

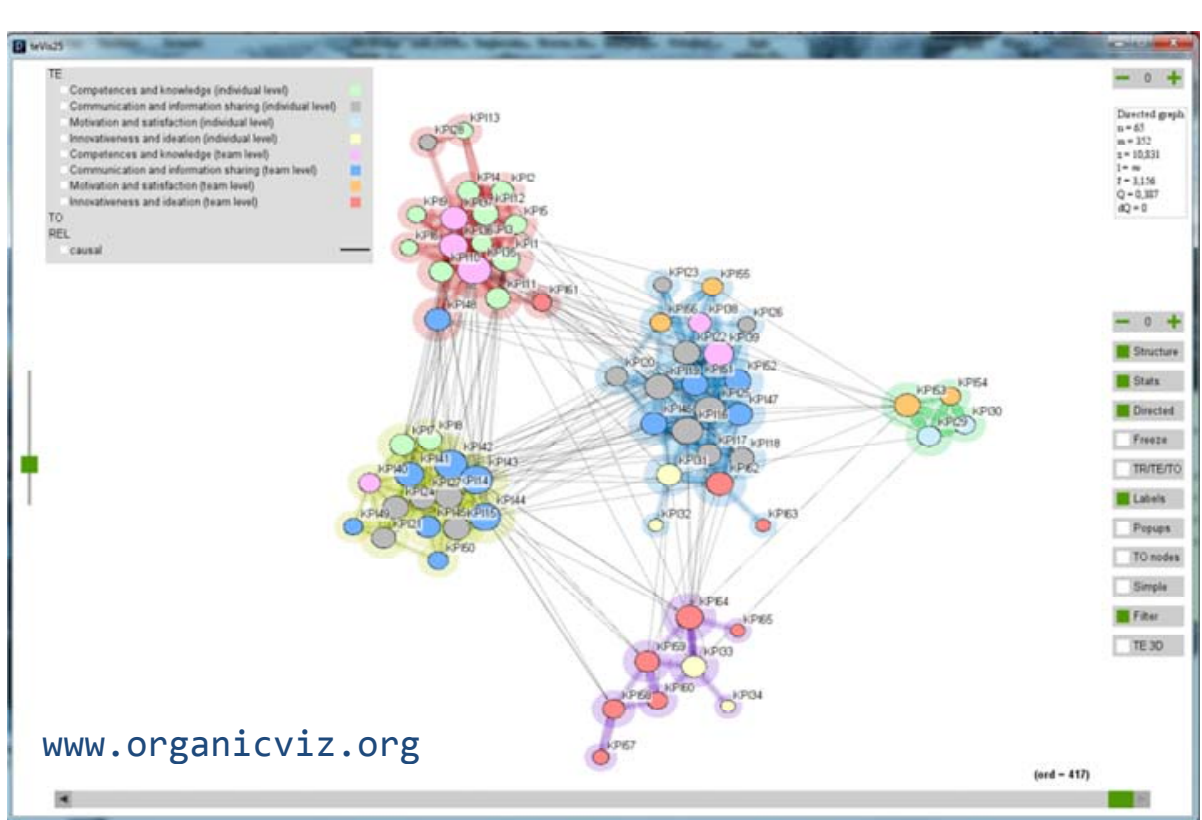

Figure 3: Key performance indicators network analysis

monitoring, every indicator from the list was analysed for its influential relations to others. Linking performance indictors resulted in network model that was further analysed for the main properties in order to understand the influential structure of the performance indicators at individual and team level. The clusters of the indictors were created in order to understand how the indicators for the individual level are contributing to the team level indicators. Also, the node degree distribution analysis was performed to identify most influential indicators and indicators with strong influence to the multiple domains. The consistency of the network was validated by group of experts from industry and academia.

\section{Conclusions}

Several benefits can be derived from results of the research so far. To start with, the list of the key performance indictors is pointing organisations toward the measures that should be applied in order to validate the performance of the specific elements of the intellectual capital across the hierarchical levels. List of $60 \mathrm{KPIs}$ that is defined and validated will be used in continuation of the project as a starting point for developing the work sampling application for real time capturing of the actual performance of individuals and teams.

Network of key performance indicators allows analysis of causal and dependency influences between indicators of the different class and hierarchical levels. By addition of the dynamics network analysis 
in addition to the analysis performed so far, the understanding of the key performance indicator values over the time could be established.

While individual performance indicators can indicate underperforming aspect of the project as well as those aspects of the business that merit increased resources and energy, management could also benefit from timely leading-indicators of emerging risks. Based on formulation of performance indicators, risk perspective could be applied based on the presumption that performance indicators which fail (have value bellow certain threshold), change their state into the risk indicators and require detailed monitoring. In addition to the existing risk indicators, causes of failed performance indicators represent second pool of risk indicators. Using forward-looking aspect of operational risk management, network consisting of key performance and key risk indicators could be offered as insightful and facilitate proactive monitoring tool for complex R\&D project management. Obtained information would promptly give indication about positive or negative trends in monitored project, emphasizing socio-technical aspects which are often neglected.

\section{Acknowledgement:}

This paper reports work funded by EUREKA E!8723 VISINEV project (www.visinev.org) and Ministry of Science and Education of Republic of Croatia.

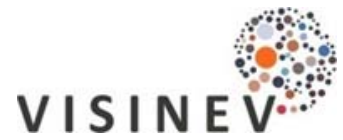

\section{References:}

1. Ackermann, F. and Eden, C. (2001). Using Causal Mapping with Computer Based Group Support System Technology For Eliciting an Understanding of Failure in Complex Projects, American Academy of Management Conference, USA.

2. Cicmil, S., Williams, T., Thomas, J. and Hodgson, D. (2006) Rethinking Project Management; Researching the Actuality of Projects, International Journal of Project Management; 24 (8)

3. Gonzaleez-Loureiro, M. and Figueroa Dorrego, P. (2012). Intellectual Capital and System of Innovation: What Really Matters at Innovative SMEs, Intangible Capital, OmniaSience; 8(2), 239-274.

4. Hall, D.C. (2011) Making Risk Assessments more Comparable and Repeatable, Systems Engineering, 14(2).

5. Hicks, B. (2013). The Language of Collaborative Engineering projects, International Conference on Engineering Design (ICED13), Seoul, South Korea

6. Noruzy, A., Majazi Dalfard, V., Azhdari, B., Nazari-Shirokouhi, S. and Rezazadeh, A. (2013). Relations Between Transformational Leadership, Organisational Learning, Knowledge Management, Organizational Innovation and Organisational Performance: An Empirical Investigation of Manufacturing Firms, International Journal of Advanced Manufacturing Technology, Springer Verlag, 64:1073-1085.

7. Remington, K. and Zolin, R. (2011). Controlling Chaos? The value and the Challenges of Applying Complexity Theory to Project Management, In Cooke-Davies, Terry (Ed.) Aspects of Complexity: Managing Projects in a Complex World, Project Management Institute.

8. Taroun, A. (2013). Towards a Better Risk Modelling and Assessment: A Critical Literature Review, The International Journal of Project Management, 32(1), 101-115.

9. Verbano, C. and Crema M. (2013). Measuring IC Following a Semi-qualitative Approach: An Integrated Framework. Intangible Capital, OmniaSience; 9(3), 539-558 